\title{
Biliary Cirrhosis
}

National Cancer Institute

\section{Source}

National Cancer Institute. Biliary Cirrhosis. NCI Thesaurus. Code C51225.

Cirrhosis of the liver caused either by destruction of the intrahepatic bile ducts (primary biliary cirrhosis) or blockage of the extrahepatic bile ducts (secondary biliary cirrhosis). 